\title{
THE EFFECTS OF P-ALAXIN ON FERTILITY AND HEMATOLOGICAL PARAMETERS IN MALE
}

ADULT WISTAR RATS

'Osonuga, Ifabunmi Oduyemi; ${ }^{2}$ Adenowo, Thomas Kehinde; ${ }^{1}$ Akindele, Raheem Akinwunmi, Idowu, Gbolahan

Departments of Physiology, Olabisi Onabanjo University, Sagamu Campus, Sagamu, Ogun State ${ }^{2}$ Department of Anatomy, Olabisi Onabanjo University, Sagamu Campus, Sagamu, Ogun State Correspondence Author E-mail: osonuga.bunmi@oouagoiwoye.edu.ng and

bunmiosonuga.bo@gmail.com

\section{ABSTRACT}

P-Alaxin, is an anti-malarial drug that is highly effective in treating malaria all forms of malarial infection including multi drug resistance malaria in areas of high resistance especially in Africa. It is therapeutic dose of P-alaxin on fertility and hematological indices in rats. Fifteen male adult Wista rats weighing between 150 and $220 \mathrm{~g}$ were divided into three consisting of 5 rats per group. Normal saline was administered to the control group while the test and recovery groups were given $15.4 \mathrm{mg} / \mathrm{kg}$ body weight of P-Alaxin orally for three days. The recovery group was allowed to recover for three days from the drug's effect. The animals were anaesthetized using diethyl ether. Blood samples were collected through cardiac puncture. Oral administration of P-alaxin (15.4mg/kg body weight) for three days reduced $(p<0.05)$ significantly the sperm motility, sperm count, viability and testosterone as well as the $\mathrm{PCV}, \mathrm{Hb}, \mathrm{BC}$ and $\mathrm{RBC}$ when compared to the control and there was no significant resulted in gradual restoration of sperm parameters and hematolocical indices under investigation. From the study it can be safely concluded that oral administration of P-Alaxin caused reduction in the hematological and sperm parameters and serum testosterone and could reduce male Wistar rats' fertility and also lead to anemia in rats

Keywords: antimalarial, sperm parameters, serum testosterone, hematological parameters.

Accepted Date: 9 June 2020

\section{INTRODUCTION}

Malaria is a mosquito-borne infectious disease of humans and other animals caused by Plasmodia and are also definitely the single most destructive and dangerous infectious agent in the developing countries of the world (Olayinka and Ore, 2013). It is an important tropical mosquito-borne infection affecting millions of people around the world and there are many health effects of this infection. Artemisinin and their derivatives have been recommended for the treatment of severe and complicated malaria. They are very active antimalaria drugs producing up to ten thousand fold reductions in parasite and they reduce 2003). P-ala in a fil coted 2003). P-alaxin is a film coated tablet containing $40 \mathrm{mg}$ of Dihydroartemisinin (DHA) and $320 \mathrm{mg}$ of piperaquine phosphate (PQP). The drug

combination is known to be effective against $P$. vivax, $P$ malariae and the multi-resistant $P$. falciparum malaria parasites. (Song et al.2003; 2011; Olayinka and Ore, 2013) Dihydroartemisinin is the active metabolite of artemisinin and its derivatives. These derivative have more potent blood schizonticidal activity tha the parent compound. Dihydroartemisinin is the most potent antimalarial of this group of compounds but it is also the least stable. Ora dihydroartemisinin is rapidly absorbed and has short elimination half-life (Song et al., 2003, Carbello et al 2011). Piperaquine phosphate, bisquinoline, structurally related to chlorequ has been shown to exhibit cardiovascular toxicity in overdose with significant electrophysiological effects on the ear (Davis et al, 2005). The of the activity of artemisinins is determined by the endo- peroxide bridge which is a specific feature of this type of compounds. It has been suggested that the parasiticidal activity starts with the reaction of artemisinins with haem iron, leading to the generation of activated oxygen species, such as oxygen radicals (Mann et al., 2005; Aprioku, 2013). Nosten and White (Nosten and White, 2007) had reported that if there is any toxicity observed in artemisinin combination treatments, it may be due to the non-artemisinin component as artemisinin derivatives alone may have relatively low toxicological effects. Decreased hematological parameters and semen quality in malarial infected male has been reported (Singer et al., 1987; Onuche and Mohammed, 2015). Many anti-malaria and antibiotic agents have been reported to have antifertility actions. The anti -steroidogenic and antifertility actions of quinine, chloroquine and artemether have been well documented (Meisel $e$ al. 1993; Adeko and Dad 1998; Raji t al. 2005 ; al., 1993; Ad Salman et al, 2010; Akno With the increased efforts in the development of more potent anti-malaria agents as a result of the challenge posed by the resistant strains of the malaria parasite, the evaluation of these antimalaria agents for possible anti-fertility actions becomes important, this is necessary since both malaria and infertility are worldwide phenomena and the need to avoid the risk of infertility resulting from malaria chemotherapy. Whereas $\mathrm{P}$-alaxin is becoming popular as an antimalarial drug with remarkable efficacy, there is paucity and conflicting information in the literature on the possible hematological as well as anti-fertility effects of its administration and this is the objective of this current study.

\section{MATERIALS AND METHODS}

\section{Experimental Design}

P-Alaxin tablet used for this project was obtained in a Pharmaceutical store in Sagamu, Ogun State, Nigeria and manufactured by Bliss GVS Pharma Limited, India. Fifteen adult male Wistar rats weighing between 150 and $220 \mathrm{~g}$ were obtained from the Animal House of the Department of Physiology, Olabisi Onabanjo University, Ikenne, Ogun State. The rats were given standard rat pellets (Top Feed Nigeria Ltd., Ibadan, Nigeria) and water ad libitum. They were housed in wire cages and under a 12 -h light and dark cycle. The control group (5 rats) was given normal saline orally. The test (5 rats) and the recovery groups (5 rats) were orally administered with $15.4 \mathrm{mg} / \mathrm{kg}$ body weight of drug each for three days. After the last administration, the test group were sacrificed by administration of diethyl ether and the recovery group was allowed to recover from the drug's effect for another three days before sacrifice.

\section{Animal Ethics:}

Ethical clearance was obtained from the departmental ethical committee and all procedures involving animals in this study conformed to the guiding principles for research involving animals as recommended by the Declaration of Helsink and the Guiding Principles (American Physiological Society, 2002) in the Use of Animals.

\section{Analytical procedure}

Twenty-four (24) hours after the last administration the animals were anaesthetized using diethyl ethe and the blood collected by cardiac puncture. Determination of serum testosterone: Serum obtained from the blood collected via cardiac puncture was used to measure the level of (EIA) technique as previously described (Raji et al., 2005).Determination of sperm viability: The sperm viability was determined using Eosin/Nigrosin stain (Raji et al., 2003; WHO, 2010). Determination of sperm motility: A simple classification system proposed by the World Health Organization (WHO, 2010), which provides the best possible assessment of sperm motility, was used. Determination of sperm count: The new improved Naubauers counting chamber was used in the deternintion of sperm count. Drops of in the determination of sper semen was applied. This was placed under light microscope and spermatozoa counted on each of the five squares (Oehninger et al., 2014). Sperm $\mathrm{pH}$ : The $\mathrm{pH}$ was determined by using narrow range litmus paper. Hematological parameters Hematology was done according to standard methods (Dacie and Lewis, 1991; Weix et al., 2014).

\section{STATISTICAL ANALYSIS}

The values are expressed as Mean \pm S.D (standard deviation of mean). The means of the groups were compared using one-way ANOVA (analysis of 
variance) and level of significance was done using east significant difference (LSD) and Duncan multiple range test (DMRT) at $\mathrm{P}<0$.

\section{RESULTS}

Effect of P-alaxin on sperm parameters is shown in Table 1.

Effect of P-alaxin on sperm parameters (sperm counts, viability, motility and $\mathrm{pH})$ : Oral administration of P-alaxin at $15.4 \mathrm{mg} / \mathrm{kg}$ body weight for three days significantly reduced $(\mathrm{p}<0.05)$ the progressive sperm motility, sperm

\begin{tabular}{|c|c|c|c|c|}
\hline Groups & Sperm motility (\%) & Sperm count $\left(10^{6} / \mathrm{mL}\right)$ & $\begin{array}{l}\text { Sperm } \\
\text { viability (\%) }\end{array}$ & ${ }_{\mathrm{PH}} \mathrm{H}$ \\
\hline Control & $83.00 \pm 4.18$ & $77.20 \pm 5.26$ & $89.00 \pm 2.24$ & $7.50 \pm 0.16$ \\
\hline Test & $73.00 \pm 5.70^{*}$ & $55.60 \pm 7.40^{*}$ & $68.00 \pm 5.70^{*}$ & $7.30 \pm 0.22$ \\
\hline Recovery & $77.00 \pm 3.54 *$ & $65.60 \pm 12.24 *$ & $81.00 \pm 3.54 *$ & $7.78 \pm 0.29$ \\
\hline
\end{tabular}

$* \mathrm{P}<0.05$ ( $\mathrm{p}$ is significant at $\mathrm{p}<0.05$ )

Table 2: Effect of P-alaxin on serum testosterone after 3 days' treatments and 3days of recovery

\begin{tabular}{ll}
\hline Groups & Testosterone $(\mathrm{nmol} / \mathrm{L})$ \\
\hline Control & $2.85 \pm 0.03$ \\
Test & $1.59 \pm 0.02^{*}$ \\
Recovery & $1.77 \pm 0.04^{*}$
\end{tabular}

$* \mathrm{P}<0.05$ ( $\mathrm{p}$ is significant at $\mathrm{p}<0.05$ ).

Table 3: Effect of P-alaxin on hematological parameters after 3 days' treatments and 3days of recovery

\begin{tabular}{|c|c|c|c|c|}
\hline Groups & PCV (\%) & 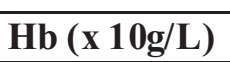 & WBC $\left(10^{9} / L\right)$ & $\operatorname{RBC}\left(10^{12} / \mathrm{L}\right)$ \\
\hline Control & $43.07 \pm 0.35$ & $14.00 \pm 0.20$ & $6.50 \pm 0.18$ & $7.0 \pm 0.30$ \\
\hline Test & $36.00 \pm 1.80^{*}$ & $7.00 \pm 1.60^{*}$ & $3.80 \pm 1.20^{*}$ & $4.70 \pm 0.60^{*}$ \\
\hline Recovery & $38.45 \pm 0.20^{*}$ & $9.70 \pm 0.86^{*}$ & $4.96 \pm 1.80^{*}$ & $5.52 \pm 0.45^{*}$ \\
\hline
\end{tabular}

$* \mathrm{P}<0.05$ ( $\mathrm{p}$ is significant at $\mathrm{p}<0.05$ ).
Discussion

Decrease in fertility after treatment of male rats with Chlorequine and Halofantrine have b reported and this may be due to impair pperm motility (Adeckoand Dad, 1998; Orisakwe et al. 2003; Rail et al., 2005; Onuche and et ah, 203; Raji et al, 2005; Onuche and Mohammed, 2015). Treatment with such antimalarial drugs results in reducing the sperm count, motility, fertility and viability, as well as in serum testosterone level. It has been advocated that these drugs caused androgen depletion at the targets levels and particularly in the cauda epididymis, thereby affecting the physiological epictical 1998). This present sudy revealed that P- ada 1998). This present study revealed that P- alaxin could cause impairment in male rats. The significant reduction in the sperm motility of rat that was treated suggests that the drug was able to permeate the blood-testis barriers. The decrease in sperm motility caused by chemical agents has earlier been reported to be due to their ability to permeates the blood-testis bearer (Orisakwe et al., 2003; Aprioku, 2013) and thus, creating a different micro environment the seminiferous tubules from that in its outer part (Bloom and Faweett, 1995). Drugs that affect the testicular functions might affect the quality and quantity of spermatozoa. The mean epididymal sperm number was significantly reduced $(\mathrm{P}<0.05)$ in all the treated groups. There was also a significant decrease in serum levels of testosterone in all the treated rats when compared with the control. The significant difference in the sperm motility, viability and counts of the rats provides coliten for the significant reductions in the evidence for androgen levels. Testosterone in association with follicle stimulating hormone, acts on the seminiferous tubules to initiate and maintain spermatogenesis (Christensen, 1975) In this study, the decreased sperm count, motility and viability, may have resulted from changes in the epididymal milieu; probably due to androgen deficiency (significant decrease in serum testosterone was observed) consequent to the anti-androgenic property of P- alaxin. Efforts were also made in this study to investigate the effect of P-alaxin on hematological parameters in male Wistar rats. We hematological parameters in male Wistar rats. We
demonstrated that administration of P-alaxin demonstrated that administration of $\mathrm{P}$-alaxin
significantly $(\mathrm{P}<0.05)$ reduced these measured parameters. Similar results were obtained by previous workers (Salako, 1984; Nontprasert et al. 2000; Shuhua et al., 2002; Osonuga et al. 2012)onpathological effects on body organs caused by oral administration of artemether and some other antimalarial agents. The changes observed in the Packed cell volume (PCV) and red blood cell count indicate that administration of P-alaxin to malaria patients may predispose them to anemia. In conclusion, P-alaxin is a form of artemisinin-besed antimalarial have hig study sugests that the admistrion study suggests that the administration of therapeutic dose of P-alaxin may predispose to male reproductive toxicity and anemia in rats. Hence caution should be taken in administering the drug.

Conflict of interest: The authors declare that there is no conflict of interest between them.

\section{REFERENCES}

Adeeko, A O and Dada O A (1998). Chloroquin reduces the fertility capacity of epididymal sperm in rats. Afri. J. Med. Med. Sci. 27:6368.

Akinsomisoye O. S and Raji Y (2011). Long-term administration of artesunate induces reproductive toxicology in male rats. $J$. Reprod. Infertil 12 (4): 249-260.

American Physiological Society (2002). Guiding principles for research involving animals and human beings. Am. J. Physiol. Regul. Integr. Comp. Physiol. 283: 281-283.

Aprioku J.S. (2013) Pharmacology of free radicals and the of reactive oxygen species on the testis. J. Reprod. Infertil 14(4): 158-172.

Bloom. E. and Faweett, D.W. (1995). Male reproductive system. In textbook of History (Ed. Bloom. W. Saunders company. Philadelphia).

Carbello, C.M, Lamore S.D, Bair W.B, Qiao S, Azimian S, Lesson J.L, and Wondrak G.T (2012). The redox antimalarial dihydroartemisinin targets human metastatic melanoma cells but not primary melanocytes with induction of NOXAdependent apoptosis. Investigational new drugs. 30 (4): 1289-1301.

Christensen, A. C. (1975). Leydig cells. In: Handbook of physiology, edited by P. O. 
Greep and E. B.A stwood. Washington D.C. American Physiological Society. 165172.

Dacie J.V.; Lewis S. M. (1991) Practical Haematology. $5^{\text {th }}$ Ed Churchill Living stone, Edinburgh. pp 13

Davis, T.M, Hung T.Y, Sim I.K, Karunajeewa H.A, Ilett KF (2005): Piperaquine: a resurgent antimalarial drug. Drugs, 65:75-87.

Mann, A., Ibrahim K., Oyewale A.O, Amupitan J.O, Okogun J.I (2009). Antimycobacterial Activity of some Medicinal Plants in Niger State, Nigeria. Afri. J. Infect. Dis, 3 (2): 4448.

Meisel. M.L., Winterh off, H.,and Jakat. F. W. (1993). Tylosin inhibits the sterio dogenesis in rat leydig cellsin-vitro. Life Science. 53:77-84

Nontprasert A, Pukrittayakamee S, NostenBertrad M, Vanijanonta S, White NJ. (2000) Studies of the neurotoxicity of oral artemisininin derivatives in mice. $\mathrm{Am}$ J. Trop.Med.Hyg 62: 409-412.

Nosten, F. and White, N.J. (2007): Artemisininbased Combination Treatment of Falciparum Malaria. Am. J. Trop. Med. Hyg., 77: 181-192.

Oehninger S, Frankein D.R, Ombelet W. (2014). Sperm functional tests. Fertility and Sterility 102: 1528-1533

Olayinka, E.T. and Ore, A. (2013). Alterations in Antioxidant Status and Biochemical Indices following Administration of Dihydroartemisinin-Piperaquine Phosphate (P-ALAXIN). Journal of Pharmacy and Biological Sciences, 5:43-

Onuche A.D and Mohammed U.K (2015). Evaluation of prolonged administration of artemether-lumenfantrine on sperm indices and testicular testosterone concentration in adult male Wistar rats. Annals of Medical and Biomedical Sciences 1(2): 56-62.

Orisakwe, O.E., Obi, E. and Udemezue, O.O. (2003) Effect of halofantrine on testicular architecture and testosterone level in guinea pigs. European Bulletin of drug Research 11:05-109
Osonuga IO, Osonuga OA, Osonuga A, Onadeko AA and Osonuga AA (2012) The Effect of Artemether on Hematological Parameter of Healthy and Uninfected Adult Wista Rats. Asian Pacific Journal of Tropic Biomedicine 1-3

White, N.J. (1999). Qinghaosu in combinations. Med. Trop. Mars 58 (3 suppl.): 85-88.

Wiex LI Z, Zhang G, Yuan H, Lv J et al., (2014). B7-H3 Promoted Sperm Motility in Humans. Urology 83: 324-330.

Salako LA (1984) Toxicity and side effects of antimalarials in Africa: a critical review. Bull World Health Organ 62: 63-68.

Salman T.M, Olayaki L.A, Shittu S.T, Bamgboye S.O (2010). Serum testosterone concentration in Chloroquine-treated rats: effects of ascorbic acid and alpha tocopheol. Afr. JBiotechnol 9 (27): 4278 4281.

Shuhua X, Yuanqing Y, Qiqing Y (2002). Potential long term toxicity of repeated orally administered doses of artemether in rats. Am J. Trop.Med. Hyg 66 (1):30-34

Singer R, Segenreich E, Sagiv M, Shohat B, Livni E, Bartoov B. (1987) Decreased semen quality in a male infected with malaria. Int $J$ Androl. 10:685-9.

Song JP, Duong S, Suou S, Thou T, Ses S, Sim Y, Tan B, Li GQ (2003): Clinical research of dihydroartemisinin-piperaquine with uncomplicated falciparum malaria. Natl Med JChina, 83:1099-1100.

Raji Y, Osonuga I. O, Akinsomisoye O. S, Osonug O. A, Mewoyeka O. O. (2005) Gonadotoxicity evaluation of oral artemisinin derivative in male rats. J. Med Sc. $5(4): 303-6$.

Raji, Y., Udoh. U.S., Mewoyeka, O.O., Ononye, F.C. Bolarinwa, A.F. (2003). Implication of reproductive endrocrine malfunction in male anti fertility efficacy of Azadiracta male anti fertility efficacy of Azact

World Health Organization, (2010). WHO Laboratory Manual for the Examination and Processing of Human Serum, $5^{\text {th }}$ ed, Geneva 